\title{
Reflexiones sobre el sistema internacional a través de los tratados de inversión ${ }^{1}$
}

\section{Reflecting about international law system using bilateral investment treaties}

\section{Susana Mosquera Monelos}

susana.mosquera@udep.pe

Doctora en Derecho. Profesora de Derecho Internacional Público, Universidad de Piura.

Resumen: La necesidad de revisar conceptos clave del derecho internacional para adaptarlo a sus nuevas circunstancias es urgente en muchos sectores, especialmente en lo que refiere a la condición de sujeto internacional. Saber quiénes serán los titulares de obligaciones internacionales y a quiénes poder reclamar responsabilidad por su incumplimiento resulta esencial en un momento en que los sectores de influencia de las normas internacionales se multiplican exponencialmente. De ahí la importancia de ofrecer argumentos que permitan responder bajo qué criterios podemos considerar a las grandes empresas multinacionales como actores internacionales. Si se toma en cuenta el papel que estas multinacionales desempeñan en la creación y el cumplimiento de las normas internacionales, la cuestión de su posición dentro del sistema internacional no es baladí, especialmente en aquellos contextos en los que su relación con el estado se establece en términos de paridad. Se trata de un tema en activa discusión en la doctrina, por lo que la aportación de este trabajo será la de ofrecer un status questionis abriendo opciones para garantizar el cumplimiento de la obligación internacional.

Palabras clave: empresas multinacionales, derecho internacional, sujetos internacionales, obligación internacional, responsabilidad.

\begin{abstract}
The necessary review of some key concepts to adapt international law to its new circumstances seems quite urgent, especially concerning the international personhood concept. Identify the owner of the international obligation to enforce the application of the international law demanding this owner responsibility, is a main question in the precise moment when the international sources of law appears everywhere. For such a reason revisiting some main concepts, as sources of law and subject, becomes relevant to be able to answer the question if, some of the new non-state actors could be granted with full international personhood. Considering the position of corporations as subject, and trade business agreements as sources of law this paper will try to offer a new focus approach to some of the main concepts of international law with the purpose to reinforce the relationship between international and domestic law.
\end{abstract}

Key words: corporations, international law, domestic law, international personhood, liability.

1 Artículo enviado el 05.08.2016 y aceptado el 12.12.2016.

Número de página no utilizable para citar 
"Reflexiones sobre el sistema internacional a través de los tratados de inversión”

Susana Mosquera Monelos

\section{Consideraciones iniciales}

\subsection{Cambio del paradigma internacional}

Dado que a lo largo de las siguientes páginas se va a platear algún que otro interrogante en relación a conceptos básicos del derecho internacional, es indispensable ofrecer como punto de arranque un pilar de apoyo conceptual que sea inmutable y seguro. Ese pilar será la evidencia fáctica de que el derecho internacional existe -aunque sea través de una muy variada y variopinta red de fuentes-, y que los Estados lo utilizan frecuentemente para establecer relaciones entre ellos $^{2}$, con el objeto de alcanzar bienes que perfeccionan a la comunidad global ${ }^{3}$. En ese sentido, si bien es cierto que nadie puede afirmar que cuando se relacionan ad extra los estados deban adoptar el mismo comportamiento que tienen ad intra ${ }^{4}$, no obstante, no sirve de excusa el argumento esquizofrénico tantas veces alegado por los estados de que su obligación internacional es incompatible con su derecho interno, y por eso no la respetan ${ }^{5}$. Quien asumió libremente una obligación tiene que cumplirla, pues no hacerlo implica la comisión de un hecho ilícito internacional ${ }^{6}$ que activará los sistemas de reclamación de responsabilidad ${ }^{7}$. Desde esa perspectiva el derecho internacional expande su definición para convertirse en un sistema normativo que establece las relaciones entre los sujetos obligados a respectar esas normas comunes, bajo sanción de responsabilidad por los actos ilícitos que deriven de su incumplimiento

La visión clásica que separaba el derecho internacional en derecho de la guerra y derecho de la paz ha sido superada ${ }^{8}$. Pero ese cambio es en realidad muy reciente. Será en 2027 cuando se

2 Como breve y básica definición de derecho internacional se puede utilizar la muy sencilla pero válida definición kelseniana de, "conjunto de normas que regulan la conducta de los estados". Hans Kelsen, Principios de derecho internacional público. (Granada: Comares, 2013), 1.

3 Sucede que sobre ese concepto de "perfección" para la comunidad global no hay consenso, de ahí que las tensiones entre los intereses de nivel local y los globales, se mantenga.

4 Es decir, que el derecho internacional no funciona igual que el derecho interno, porque en sus relaciones exteriores los estados tienen otras reglas de juego: esas que regula el derecho internacional.

5 En este sentido el art. 27 de la Convención de Viena sobre el derecho de los tratados, que entró en vigor el 27 de enero de 1980, es muy claro: "Una parte no podrá invocar las disposiciones de su derecho interno como justificación del incumplimiento de un tratado". Sirva como dato complementario, que se trata de una regla constante en la costumbre internacional que el texto de la Convención vino a cristalizar, pero no a crear. "Convención de Viena sobre el derecho de los tratados", 23 de mayo de 1969.

6 Sirva como aclaración, que el hecho ilícito no es la negación de la norma internacional sino que es la condición para la sanción por incumplimiento de la norma. Así, el sujeto vinculado por la obligación internacional, será el posible autor de ese hecho ilícito al que se reclame responsabilidad. O como señala la Resolución 56/83 en su art. 2: "Hay hecho internacionalmente ilícito del Estado cuando un comportamiento consistente en una acción u omisión: a) Es atribuible al Estado según el derecho internacional; y b) Constituye una violación de una obligación internacional del Estado".

7 James Crawford y Jeremy Watkins, "International Responsibility", en The Philosophy of International Law, eds. Samantha Besson y John Tasioulas (Oxford: Oxford University Press, 2010), 283-298.

8 Los libros de los principales académicos del derecho internacional público a principios del siglo XX tenían esa división esencial. Y no era extraño encontrar una mayor atención a la normativa bélica que al derecho que regulaba las relaciones

Número de página no utilizable para citar 
cumplan los 100 años del pacto Briand-Kellog, primer compromiso serio de erradicar la guerra como sistema de solución de controversias. Y es que si se considera detenidamente, no hace tanto tiempo que las relaciones entre los estados han adoptado nuevos modos. Modos desconocidos en la historia de la comunidad internacional que está plagada de pactos secretos, de guerras de poder y conquista, para gloria y prestigio del gobernante de turno. La incorporación en el art. 2.4 de la Carta de Naciones Unidas de una prohibición expresa de recurrir a la amenaza o uso de la fuerza es una novedad absoluta para el derecho internacional, que obliga a luchar contra la tendencia natural de los estados, acostumbrados a usar la fuerza para resolver sus controversias?.

Pero es que ese no ha sido el único cambio. Eliminar el uso de la fuerza obliga a los estados a establecer sistemas alternativos -alternativos a la declaración de guerra- para resolver sus controversias, y la necesidad de que sean sistemas independientes y autónomos, que garanticen el trato en igualdad de los estados, impulsa la creación de organizaciones internacionales sectoriales, dedicadas a fortalecer la cooperación entre los estados y a servir de foro de discusión y solución de controversias ${ }^{10}$. El problema añadido es que los problemas son muchos y son nuevos, porque jóvenes estados ${ }^{11}$ se han incorporado a esa comunidad al mismo tiempo que han surgido desconocidos campos de acción para el derecho internacional ${ }^{12}$. Y sin embargo, la raíz de ese sistema jurídico sigue anclada a un concepto de fuentes que recibe su fuerza vinculante del consentimiento expresado libremente por el estado como sujeto primario y esencial del sistema ${ }^{13}$. Un derecho internacional hecho por estados para los estados tenía sentido hace un siglo, pero ya no ${ }^{14}$. Ese Estado, con sus virtudes y defectos, estaba preparado para dialogar -o golpear si fuera necesario- a uno de sus iguales, pero las actuales circunstancias del derecho internacional dificultan su actuación en el plano internacional, pues no siempre está dispuesto a interactuar con entes no estatales -organizaciones internacionales, persona humana o empresas multinacionales-, pero que sin lugar a dudas desempeñan un papel relevante en el nuevo modelo de relaciones internacionales.

entre los estados en tiempos de paz. Véase por ejemplo la obra de A. Bello. Principios de derecho de gentes. Santiago de Chile. 1832; y también C. Calvo. Derecho internacional teórico y práctico en Europa y América. París. D’Amyot. 1868.

9 Sobre el uso de la fuerza, su construcción como teoría y posterior desarrollo véase, Ian Browlie, "International Law of the Use of Force by States Revisited", Chinese Journal of International Law 1(1) (2002): 1-19.

10 Cfr. B. A. Simmons y L.L. Martin, "International Organizations and Institutions", en W. Carlnaes, Th. Risse \& B.A. Simmons, Handbook of International Relations, (SAGE. 2002), pp. 192-21.

11 Sirva como elemento de referencia la comparativa entre en número de estados miembro de la Sociedad de Naciones, 63, frente a los 193 de las Naciones Unidas en la actualidad. De ellos unos 70 surgieron del proceso descolonizador impulsado por las Naciones Unidas tras la II Guerra Mundial.

12 Las telecomunicaciones, la navegación aérea o la carrera espacial solo por mencionar alguno de los más llamativos y exigentes en la necesidad de coordinar intereses comunes de la humanidad.

13 Sobre la regla de consentimiento ha hablado mucho Kelsen cuestionando seriamente que en ella resida la validez del derecho internacional. Ofreciendo como alternativa una visión unitaria del derecho nacional y del derecho internacional que descansa en un concepto de soberanía que envía sus efectos hacia dentro, pero que se construye ad extra, en la alteridad con otros iguales - con otros estados que reconocen al nuevo como legítimo titular de soberanía estatal. Kelsen, Principios de derecho penal público, 13.

14 Wolfgang Friedman, The Changing Structure of International Law, (Nueva York: Columbia University Press, 1964$), 70$. 
"Reflexiones sobre el sistema internacional a través de los tratados de inversión"

Susana Mosquera Monelos

\subsection{Necesidad de aggiomamento del sistema}

El derecho internacional vive un momento de expansión pero sigue gobernando con un sistema de fuentes basado en el paradigma clásico del estado como creador y destinatario único de ese derecho. Cuando en la práctica la realidad viene a demostrar que esas nuevas materias, derechos humanos, derecho criminal internacional o acuerdos comerciales internacionales, están destinadas a la persona humana, a los grupos y a las empresas multinacionales y no solo al estado. De ahí que sean muchos los autores que hablan de la necesidad de actualizar y revisar el sistema internacional; pero las soluciones no son evidentes ni fáciles de $\operatorname{adoptar}^{15}$.

La fuente principal en derecho internacional siguen siendo los tratados. Su éxito viene demostrado en la práctica por su proliferación en todas las áreas geográficas y temáticas. Sin embargo, preparar tratados sigue siendo una labor complicada ${ }^{16}$ y lograr su entrada en vigor una tarea ardua; que tiene además el problema añadido de las dificultades, -reales o imaginarias a veces-, que encuentran los estados a la hora de adaptar el texto del tratado a las realidades jurídicas nacionales ${ }^{17}$. Prueba de la dificultad que existe para hacer derecho internacional escrito, es el importante papel que desempeña la costumbre dentro del sistema de fuentes de derecho internacional. Así los tribunales internacionales ${ }^{18}$ recurren a la analogía con los principios que también existen en el derecho nacional, para cubrir las lagunas normativas que deja en el sistema jurídico internacional la ausencia de un tratado en vigor o la imposibilidad de probar una regla consuetudinaria. Confirmando de este modo la idea de que derecho internacional y derecho interno no son realidades jurídicas separadas ${ }^{19}$.

15 Cfr. Philip Allot, "The Concept of International Law”, European Journal of International Law 10 (1999): 31-50. También, Cristoph Schreuer, "The Waning of the Sovereign State: Towards a New Paradigm for International Law?", European Journal of International Law 4 (1993): 447-471.

16 Las negociaciones multilaterales son lentas y complicadas, pero hacer tratados bilaterales tampoco es una solución pues con los 193 estados miembros que componen actualmente las Naciones Unidas saldría una cifra de 37.000 tratados; lo que haría totalmente inmanejable su control.

17 En el caso Whitney v. Robertson, la Corte Suprema de los Estados Unidos, un país nada sospecho de tener una excesiva Amistad hacia el derecho internacional precisaba, ya en 1888, sobre la naturaleza auto ejecutiva o no del tratado lo siguiente: "Un tratado es en primer término un contrato entre dos o más naciones independientes, y está relacionado a temas de derecho público. (...) Cuando las disposiciones del tratado no son auto-ejecutivas, solo podrán ser aplicada a través de normas que las desarrollen. (...) Si el tratado contiene disposiciones auto-ejecutivas, que no necesitan de norma de desarrollo para hacerlas operativas, en ese punto se le considerará como promulgación legislativa". (Traducción propia). Whitney v. Robertson, 124 U.S. 190 (1888).

$18 \mathrm{Y}$ a pesar de que no existe un sistema de precedentes en derecho internacional, la jurisprudencia se nutre de esas fuentes. Muy frecuentemente son usados en los procesos de arbitraje internacional. Cfr. Christoph Schreuer y Matthew Weiniger, “A Doctrine of Precedent?", en The Oxford Handbook of International Investment Law, eds. Peter Muchlinski, Federico Ortino, y Christoph Schreue (Oxford: Oxford University Press. 2008), 188-206.

19 La estrecha relación que hay entre las distintas fuentes se confirma también cuando comprobamos que la comunidad de abogados especialistas en derecho internacional se compone de profesores que se convierten en jueces y árbitros de instancias internacionales, o asesoran a los gobiernos en temas de derecho internacional.

Número de página no utilizable para citar 
Junto a las fuentes clásicas, convenciones, costumbre, principios generales, y los medios auxiliares que menciona el art. 38 del $\mathrm{ECIJ}^{20}$ resulta que el derecho internacional en su nuevo paradigma se nutre además de otro tipo de fuentes difíciles de catalogar y de analizar. Se las presenta como soft law $w^{21}$ en un supuesto intento de diferenciarlas de las que están enumeradas en el art. 38 que serían entonces "el bloque rígido del derecho internacional" ${ }^{22}$. Distinción que conviene mucho a los estados, pues de ese modo seguirán siendo ellos los que atesoran la capacidad para crear derecho rígido, derecho verdaderamente vinculante. De esa capacidad normativa derivan su condición de sujeto internacional, y de ese modo, sistema de fuentes y subjetividad internacional se convierten en las dos caras de una misma moneda que siempre va a caer del lado del estado.

Pero, ¿qué sucedería si varía el enfoque y el eje del derecho internacional se desplaza un poco más allá de la creación de la norma, enfocando hacia su cumplimiento? Surge entonces la necesidad de considerar el concepto de obligación, visualizar quienes son los que deben cumplirla y qué consecuencias tiene olvidarse de la existencia de esa norma; se estaría apuntando hacia el sistema de responsabilidad internacional. Y eso es jugar en otra liga, donde el concepto de sujeto se expande no solo para incluir a los nuevos estados, sino para incorporar a la persona, a los grupo y organizaciones de la sociedad civil, a las empresas multinacionales, entre otros muchos; y donde las fuentes surgen tanto de la regla de consentimiento, como de otros mecanismos que no tienen su origen en el tratado ${ }^{23}$. Llevando el foco hacia la reclamación de responsabilidad, la consecuencia necesaria es la preocupación por activar sistemas de solución de controversias que resulten eficaces y satisfagan a todos los implicados en el litigio ${ }^{24}$.

La duda a resolver es por tanto: ¿soy sujeto internacional porque tengo capacidad para crear la norma o porque estoy sometido a su cumplimiento y por tanto me pueden reclamar responsabilidad internacional cuando no la cumplo? Para comprobar si ese enfoque -centrado en la responsabilidad- funciona, se tomará como campo de prueba el derecho internacional de inversiones pues reúne buena parte de los rasgos que propician esta nueva y diferente visión del sistema internacional. Tiene un origen consuetudinario, que se evidencia en reglas aún vigentes ${ }^{25}$

Estatuto de la Corte Internacional de Justicia.

21 De todas las posibles fuentes que reciben la calificación de soft law ninguna más famosa que las resoluciones de las organizaciones internacionales que evidentemente no están mencionadas en la lista del art. 38 ECIJ porque en esa fecha la CIJ aún no había resuelto la duda de si estas organizaciones disfrutaban de una subjetividad internacional autónoma de la de sus estados miembros.

22 La distinción tiene en realidad detrás de ella la idea clásica que sutilmente filtran los estados, de que solo el derecho internacional que ha recibido expreso consentimiento nacional es derecho vinculante. Vid. Hartmut Hillgenberg, "A Fresh Look at Soft Law", European Journal of International Law 10 (1999): 499-515.

23 Karsten Nowrot, "New Approaches to the International Legal Personality of Multinational Corporations Towards a Rebuttable Presumption of Normative Responsibilities", ESIL-SEDI Forum, http:/ /www.esilsedi.eu/sites/default/files/Nowrot.PDF, [consulta: 8.may.2017].

24 Vid. Janne Nijman, "Non-State Actors and the International Rule of Law: Revisiting the 'Realistic Theory' of International Legal Personality", en Non-State Actor Dynamics in International Law. From Law-Takers to Law-Makers, eds. Math Noortman y Cedric Ryngaert, (London \& New York: Routledge, 2016), 91-124.

25 Reglas de procedimiento que protegen al inversor extranjero como la protección contra la propiedad expropiada, o el cumplimiento de los contratos entre inversionista y estado huésped. 
"Reflexiones sobre el sistema internacional a través de los tratados de inversión"

Susana Mosquera Monelos

pero se nutre de una muy numerosa red de acuerdos internacionales; además, en él, han impactado con fuerza los acontecimientos históricos que desde fines del siglo XIX han cambiado la fisonomía del derecho internacional ${ }^{26}$. Es por eso que a día de hoy, presenta todos los elementos de este cambio de paradigma: nuevos actores, nuevo sistema de fuentes, nuevas reglas de solución de controversias ${ }^{27}$. Después de analizar este nuevo y complejo sector del derecho internacional habrá que ofrecer una respuesta a la pregunta de si conviene más ampliar el concepto de subjetividad internacional para incorporar en él a las empresas multinacionales y otros nuevos sujetos con capacidad de obrar en sede internacional, o si a través de otros mecanismos, como los de la responsabilidad internacional podemos encontrar acomodo a las actuales exigencias del sistema internacional. A plantear esta cuestión se dedicarán las siguientes páginas.

\section{Las empresas multinacionales en el Derecho Internacional}

Aunque en derecho interno la palabra corporación puede tener un significado jurídico muy variado, cuando se usa en derecho internacional es para hacer referencia a las empresas que se dedican a las actividades comerciales ${ }^{28}$. Y ya desde el caso Barcelona Traction (1970) la CIJ ha reconocido que para el derecho internacional existe una personalidad de la corporación separada de aquella que tienen sus socios. El fenómeno de la globalización ${ }^{29}$, con empresas que interactúan en múltiples sedes, ha incrementado el número de normas que desde el derecho internacional observan a las empresas multinacionales, y con ello el número de casos de conflicto en las relaciones entre estas y los estados que las acogen ${ }^{30}$.

26 El conflicto colonial de fines del siglo XIX, la llegada de las ideologías socialistas, el proceso descolonizador.

27 "La situación es caótica; y la confusión no se resuelve tratando a las empresas multinacionales como si fuesen personas humanas. Es necesario reconocer que son entidades sui generis y que las reglas que se les aplican deben responder a las funciones que desempeñan", (traducción propia). Cit. Vaughan Lowe, "Corporations as International Actors and International Law Makers", en Italian Yearbook of International Law, vol. XIV, ed. Benedetto Conforti (Martinus Nijhoff Publishers, 2004), 36.

28 El término corporaciones es el que se utiliza más frecuentemente en la producción académica iusinternacional de habla inglesa, mientras que en los países de habla hispana el término de referencia es el de empresas multinacionales.

29 Las últimas décadas han sido testigos de un dramático aumento de los negocios globales. Hoy en día se estima que unas 100.000 empresas multinacionales son responsables de una cuarta parte del producto nacional bruto y generan beneficios que superan el presupuesto público de muchos estados. El sector privado tiene un importante poder económico y social, incluso en sectores que tradicionalmente han estado bajo el control estatal, desarrollando de ese modo funciones cuasi estatales en el sector de las infraestructuras servicios de salud o incluso en la organización del proceso electoral. UNCTAD, World Investment Report: Non-Equity Modes of International Production and Development, UN Doc UNCTAD/WIR/2011, 24, http://unctad.org/en/PublicationsLibrary/wir2011_en.pdf, [consulta: 8.may.2017].

30 La controversia está servida, pues frente a la tendencia a conceder beneficios y ventajas que favorecen la inversión extranjera, los estados huésped tienen el deber de atender las denuncias, presentadas por sus nacionales o por terceros afectados, por abusos que estas empresas pueden haber cometido dentro del territorio de ese estado.

Número de página no utilizable para citar 


\subsection{Enfoque clásico de la relación entre empresas multinacionales y Estado huésped}

La visión tradicional de las empresas multinacionales para el derecho internacional es que se trataba de entidades creadas en sede nacional que por tanto no podían tener reconocimiento internacional. De ahí que cuando era necesario proteger a la entidad frente a algún tipo de abuso cometido por el estado huésped, se activaban los mecanismos de la protección diplomática ${ }^{31}$, creados porque no había en ese derecho internacional clásico ningún instrumento que protegiese los derechos del individuo ${ }^{32}$. Se trataba de un mecanismo de protección con graves deficiencias, que para su utilización dependía completamente de la decisión discrecional del estado de nacionalidad de la corporación, y que obligaba a esta al agotamiento previo de los recursos disponibles dentro del sistema jurídico del estado huésped ${ }^{33}$. No obstante sus dificultades prácticas, fue un mecanismo con bastante uso durante el siglo XIX especialmente si se le acompañaba de la "diplomacia bélica" tan frecuente en esos momentos ${ }^{34}$.

Los principales ejemplos de ese tipo de protección diplomática, que no descartaba el uso de la fuerza, vienen de las intervenciones de Francia, Reino Unido y los Estados Unidos ante expropiaciones sufridas por sus nacionales en América Latina. Como reacción, los países latinoamericanos respondieron fortaleciendo un concepto que todavía atesoran como gran valor, el no intervencionismo; al mismo tiempo que avezados juristas de la época desarrollaron mecanismos legales para equilibrar las fuerzas. Entre todos debe destacarse la labor del jurista argentino Carlos Calvo que puso su nombre a la más famosa cláusula de exclusión de la regla de protección diplomática ${ }^{35}$. La aplicación de la cláusula Calvo afectaba principalmente a los

31 Aunque ciertamente no podemos decir que sea un problema nuevo pues ya a fines del Siglo XVIII Vattel ofrecía su máxima clásica de quien trata mal a un ciudadano indirectamente perjudica al Estado que debe protegerlo. Cfr. Emer de Vattel, The Law of Nations, or the Principles of Natural Law Applied to the Conduct and Affairs of Nations and Sovereigns (Philadelphia: T \& J.W. Johnson. Law Booksellers, 1844). Principio que recibió el respaldo de la Corte Permanente de Justicia International en 1924 en la causa sobre las concesiones Mavrommatis en Palestina, en la que la Corte afirmó que: "Al asumir la causa de uno de los suyos, al poner en marcha, en su favor, la acción diplomática o la acción judicial internacional, ese Estado hace valer, en realidad su propio derecho, el derecho que tiene a hacer respetar en la persona de sus súbditos el derecho internacional”. CASO DE LAS CONCESIONES MAVROMMATIS EN PALESTINA (Grecia con Reino Unido), (Informes de la C.P.J.I. 1924), Serie A, núm. 2, 12.

32 Y la lógica del derecho internacional establecía la bilateralidad estado-estado como regla para activar mecanismos de solución de controversias.

33 Que el estado de nacionalidad de la empresa se decidiese a proteger a su nacional -no a la persona natural sino a la jurídica- dependía en gran medida de cómo fuese a afectar a las relaciones bilaterales con el estado huésped. Con la dificultad añadida que tiene establecer el vínculo de nacionalidad de las personas jurídicas.

34 De hecho, aunque Vattel ya habló a fines del siglo XVIII del deber del estado de proteger a sus ciudadanos, la protección diplomática como mecanismo de derecho internacional tiene su origen en la segunda mitad del siglo XIX, y fue especialmente utilizado en el contexto latinoamericano. Vid. Luis Podesta, Manual de derecho internacional público, (Buenos Aires: (s.e.), 1947), 199. "These claims would be honored through diplomatic negotiation, international arbitration, economic or political pressure, or sometimes through the use of armed force". Donald Shea, The Calvo Clause. A Problem of Inter-American and International Law and Diplomacy (Minneapolis: University of Minnesota Press, 1955), 28.

35 Aunque la también el gran jurista venezolano Andrés Bello planteaba con similares argumento una aplicación de ese no intervencionismo que llevara los litigios siempre a la sede judicial del estado huésped. Recientemente la CIJ ha tenido la oportunidad de analizar la figura de la protección diplomática "por sustitución” en el caso Ahmadon Sadio Diallo llegando a la conclusión de que el Derecho internacional consuetudinario no ampara tal figura. Cfr. Ahmadou Sadio Diallo (Republic of Guinea v. Democratic Republic of the Congo), Preliminary Objections, Judgment, I.C.J. Reports 2007, p. 582.

Número de página no utilizable para citar 
"Reflexiones sobre el sistema internacional a través de los tratados de inversión"

Susana Mosquera Monelos

inversionistas extranjeros, no a los ciudadanos extranjeros que residían en el estado huésped ${ }^{36}$; y todavía sigue activa en algunos textos constitucionales latinoamericanos ${ }^{37}$ y en las relaciones contractuales que se negocian con inversionistas extranjeros ${ }^{38}$.

Las controversias por incumplimiento de los contratos de inversión pactados entre estado y empresas extranjeras eran frecuentes, y solucionarlas no era labor sencilla. Los argumentos que esgrimía cada parte para justificar la aplicación de su derecho en el conocimiento del caso eran incompatibles ${ }^{39}$. Mientras que los inversionistas hablaban de los derechos adquiridos y de la santidad de los contratos, el estado huésped planteaba la naturaleza injusta de los contratos y su permanente soberanía sobre los recursos naturales. Con esos argumentos, y después de un siglo de controversias con intervención diplomática o bélica de las potencias occidentales para proteger intereses de sus nacionales, se llega a 1962 cuando la Asamblea General de las Naciones Unidas aprueba la resolución 1803 (XVII) sobre Soberanía permanente sobre los recursos naturales que establecía una compensación apropiada en materia de expropiaciones o nacionalizaciones. Y aunque Estados Unidos quiso interpretar ese "apropiada" como una confirmación de su Hull rule $^{40}$, la Asamblea General en la resolución 3171 (XXVIII) del 5 de febrero de 1974 lo dejó bien claro, en términos poco amistosos para la regla $\mathrm{Hull}^{41}$. Si a esta interpretación pro-estado huésped añadimos el clima de incertidumbre política y de inestabilidad económica de los años 80 del siglo $\mathrm{XX}$, se entiende la razón de que por medio de reglas particulares-incorporadas a través de los

36 Vid. L. M. Summers, “The Calvo Clause”, Virginia Law Review 19(5) (1933): 459-484.

37 Artículo 63 de la Constitución peruana de 1993.- "Inversión nacional y extranjera: La inversión nacional y la extranjera se sujetan a las mismas condiciones. La producción de bienes y servicios y el comercio exterior son libres. Si otro país o países adoptan medidas proteccionistas o discriminatorias que perjudiquen el interés nacional, el Estado puede, en defensa de éste, adoptar medidas análogas. En todo contrato del Estado y de las personas de derecho público con extranjeros domiciliados consta el sometimiento de éstos a las leyes y órganos jurisdiccionales de la República y su renuncia a toda reclamación diplomática. Pueden ser exceptuados de la jurisdicción nacional los contratos de carácter financiero. El Estado y las demás personas de derecho público pueden someter las controversias derivadas de relación contractual a tribunales constituidos en virtud de tratados en vigor. Pueden también someterlas a arbitraje nacional o internacional, en la forma en que lo disponga la ley".

38 Vid. Christoph Schreuer, "Calvo's Grandchildren: The Return of Local Remedies in Investment Arbitration", Law and Practice of International Courts and Tribunals 4(1) (2005): 1-17.

39 Ya desde el siglo XVIII Estados Unidos inició la práctica de establecer acuerdos bilaterales de amistad, comercio y navegación en los que incluían disposiciones para garantizar "protección especial" para las propiedad de los nacionales de un estado parte en el territorio de otro estado parte, al tiempo que establecían un pago en compensación en caso de expropiación, entre otros aspectos de protección diplomática. (Traducción propia) Treaty of Friendship, Commerce, and Navigation, U.S.-Para., art. IX, Feb. 4, 1859, 12 Stat. 1091; Treaty of Friendship, Commerce, and Navigation, U.S.-Arg., art. VII, July 27, 1853, 10 Stat. 1005; Treaty of Friendship, Commerce, and Navigation, U.S.-Costa Rica, art. VII, July 10, 1851, 10 Stat. 916. Cfr. Kenneth J. Vandevelde. "A Brief History of International Investment Agreements", en Journal of International Law \& Policy, Vol. 12(1), (2005), pp. 157-194.

40 El requisito de una compensación completa en caso de expropiación fue desarrollado en la década de 1930 a raíz de una serie de confiscaciones que el Gobierno de México hizo contra ciudadanos estadounidenses. La formuló el Secretario de Estado, Cordel Hull y estableció los requisitos indispensables: pronta, adecuada y efectiva, que todavía hoy en día permiten calificar la compensación como completa. Vid. Suzy Nikiema, "Compensation for Expropriation", International Institute for Sustainable Development, http://www.iisd.org/pdf/2013/best_practice_compensation_expropriation_en.pdf [consulta: 8.may.2017].

41 "Afirma que la aplicación del principio de la nacionalización por los estados, como expresión de su soberanía para salvaguardar sus recursos naturales, implica que cada estado tiene derecho a determinar el monto de la posible indemnización y las modalidades de pago, y que toda controversia que pueda surgir deberá resolverse de conformidad con la legislación nacional de cada uno de los estados que apliquen tales medidas".

Número de página no utilizable para citar 
acuerdos bilaterales de inversión-, se avanzase hacia un nuevo enfoque de las relaciones entre inversionista y estado huésped.

\subsection{El contexto actual: los acuerdos bilaterales de inversión}

Los primeros acuerdos bilaterales de inversión ${ }^{42}$ se suscriben a mediados del siglo XX con el objeto de proteger la inversión privada. Hoy están vigentes más de 3000 acuerdos de inversión con poca uniformidad entre ellos pero varios temas comunes: aplicación personal y temporal, definición de la inversión, tratamiento de la inversión extranjera, expropiación, libertad de transferencia de divisas y mecanismos de arreglo de controversias ${ }^{43}$. Adicionalmente, muchos incluyen cláusulas de protección que obligan a las partes contratantes -estados- a elevar a la condición de regla internacional las obligaciones contractuales que hayan adoptado con personas naturales o jurídicas en el marco de aplicación del acuerdo. No parece posible encontrar en estos momentos otro mecanismo más radicalmente trasgresor de las reglas clásicas que rigen el sistema de fuentes de derecho internacional que el hecho de que un acto de gestión del estado con un particular, termine convertido en norma adscrita al tratado internacional del que nunca formó parte originalmente y al que no se une en forma de protocolo facultativo, sino a través de un acto de gestión -ni siquiera de un acto legislativo- del estado huésped.

Pero sin lugar a dudas los mecanismos de solución de controversias son lo más destacado de los nuevos acuerdos de inversión, en tanto que ofrecen a los inversores de la posibilidad de presentar demandas directas contra el estado huésped; lo que representa un poderoso mecanismo de cumplimiento del acuerdo internacional ${ }^{44}$. Considerando además, que la elección del foro, nacional o arbitraje internacional ${ }^{45}$, queda en manos del inversionista y comprenderán la importancia que este mecanismo de cumplimiento de tratados tiene en el derecho internacional actual $^{46}$.

Esa importancia de los acuerdos bilaterales de inversión como fuente del derecho internacional está directamente relacionada con la importancia de las empresas multinacionales como actores no estatales del derecho internacional. El número de acuerdos habla del número de empresas

42 Conocidos por sus siglas en inglés como BIT. Aunque conocen muchas formulaciones y dentro de ellos se puede colocar a los TLC, muy comunes en América Latina.

43 Cfr. I. Wonter \& A. L. Chané, "Multinational Corporations in International Law", Working Paper 129. Leuven Center for Global Governance Studies. Diciembre, 2013,

https://ghum.kuleuven.be/ggs/publications/working_papers/new_series/wp121-130/wp129-wouters-chane.pdf, [consulta: 8.may.2017].

44 Como también se ha demostrado en el caso de los tratados de derechos humanos que cuentan con un sistema de queja directa de la víctima contra el estado.

45 La elección suele estar entre la UNCITRAL (Comisión de las Naciones Unidas para el Derecho Mercantil) y el ICSID (Centro Internacional de Arreglo de Diferencias Relativas a Inversiones).

46 Peter Muchlinski, "Multinational Enterprises as Actors in International Law. Creating 'Soft Law' Obligations and 'Hard Law' Rights", en Non-State Actor Dynamics in International Law. From Law-Takers to Law-Makers, eds. Math Noortman y Cedric Ryngaert, (London \& New York: Routledge, 2016), 9-40.

Número de página no utilizable para citar 
transnacionales que gestionan servicios de todo tipo en todo el mundo de la mano de este tipo de acuerdos. De ahí la necesidad de completar la regulación de este sector con normas que no siempre pueden incluirse dentro del tratado de inversión ${ }^{47}$, con el objeto abrir la opción de una posible reclamación de responsabilidad contra las empresas. Los sectores más sensibles son el de la responsabilidad corporativa en materia de derechos humanos ${ }^{48}$, protección ambiental ${ }^{49}, y$ responsabilidad criminal de las empresas multinacionales ${ }^{50}$.

El ejemplo que puede ilustrar todos esos elementos se encuentra justamente en Perú. Un panel de la UNCITRAL -aunque el procedimiento lo administrará el ICSID ${ }^{51}$ y tiene audiencias públicas- está listo para revisar la demanda de 800 millones de dólares que el grupo Renco, como inversionista extranjero, ha presentado contra el estado ${ }^{52}$. Es la primera demanda inversionistaestado planteada con base en el mecanismo de solución de controversias establecido en el TLC Perú-Estados Unidos, que entró en vigor en 2009. Paralelamente el grupo Renco y sus filiales enfrentan una demanda ante los tribunales de Missouri por los daños sufridos por un grupo de niños expuestos a altos niveles de contaminación en La Oroya ${ }^{53}$. Mientras que ante la Comisión Interamericana de Derechos Humanos es el estado el que ha sido denunciado por no haber hecho lo suficiente para proteger la salud de los pobladores. La colisión en este caso -o grupo de casos- de temas de derechos humanos, derecho ambiental y tratados de inversión lo convierte

47 Aunque a veces las reservas al tratado son un buen mecanismo para modular la obligación del estado huésped, al igual que la petrificación del tratado o la exclusión de su efecto auto-ejecutivo como a veces se ha hecho. Herramientas que están en manos del estado soberano, pero no siempre son bien recibidas por los otros interesados en el cumplimiento del tratado.

48 La designación en 2005 de un Represente Especial del Secretario General de las Naciones Unidas para Empresas y Derechos Humanos y la aprobación en 2011 de los Principios Rectores sobre las empresas y los Derechos Humanos, demuestra el interés que hay en relación a esta delicada cuestión. Vid. Marion Weschka, "Human Rights and Multinational Enterprises: How Can Multinational Enterprises Be Held Responsible for Human Rights Violations Committed Abroad?”, Heidelberg Journal of International Law 66, (2006), http://www.zaoerv.de/66_2006/66_2006_3_a_625_662.pdf, [consulta: 8.may.2017].

49 La importancia de una adecuada implementación de las normas internacionales en materia ambiental se demuestra al comprobar que solo es posible demandar a las empresas multinacionales por daño ambiental en sede nacional. Y es que aunque en el marco de los tratados de inversión se haya reconocido a las empresas multinacionales locus standi, hay todavía un largo trecho que las separa de la subjetividad internacional. Cfr. Gregory Rose, "Gaps in the Implementation of Environmental Law at the National, Regional and Global Level", First Preparatory Meeting of the World Congress on Justice, Governance and Law for Environmental Sustainability, Programa de Naciones Unidas para el Medioambiente, 12-13 de octubre de 2011. Vid. Michael Ewing-Chow y Darryl Soh, "Pain, Gain, or Shame: the Evolution of Environmental Law and the Role of Multinational Corporations", Indiana Journal of Global Legal Studies 16 (1) (2009): 195-222.

50 Cfr. Edward Diskant, "Comparative Corporate Criminal Liability: Exploring the Uniquely American Doctrine Through Comparative Criminal Procedure”, The Yale Law Journal 118 (2008): 126-176.

51 Perú suscribió la Convención constitutiva del Centro Internacional de Arreglo de Diferencias Relativas a Inversiones en 1991.

52 The Renco Group, Inc. v. Republic of Peru (ICSID Case No. UNCT/13/1).

53 La mina de La Oroya, situada una de las ciudades más contaminadas del mundo, ha estado administrada por la minera Doe Run Perú desde 1997 hasta 2009. En ese tiempo la empresa, filial del Grupo Renco en Perú acumuló sanciones por incumplimiento ambiental y demandas por daño a la salud de los pobladores de la zona, hasta que inició un proceso de quiebra en el que participa el estado peruano como deudor de 120 millones de US \$ que la empresa se había comprometido a invertir en una planta de tratamiento de residuos mineros. De ese modo encontramos a los mismos actores: empresa, estado, pobladores, trabajadores, interactuando judicialmente entre ellos en distintas sedes, generando con ello un gran nivel de dificultad para solucionar la situación de ese complejo económico. 
en experimento perfecto para comprobar si en efecto el modelo de derecho internacional funciona o necesita de algunos ajustes esenciales ${ }^{54}$.

Es de todos conocido que Perú, ha venido desarrollando en las últimas décadas, una política sólida y estable para atraer inversiones. La suscripción de diversos instrumentos internacionales, contratos y convenios de inversión, junto al crecimiento económico del país en los últimos años, ha logrado que se incremente de forma considerable la inversión extranjera directa ${ }^{55}$ Pero atraer inversión extranjera, también implica atraer pleitos con empresas extranjeras. De ahí, la promulgación de la Ley N 28933 en 2006, creando el Sistema de Coordinación y Respuesta del Estado en Controversias Internacionales de Inversión ${ }^{56}$. También es uno de los 181 estados miembro de la MIGA (Organismo Multilateral de Garantía de Inversiones creado en 1988) que desde el Banco Mundial ofrece apoyo para la negociación y aplicación de los BIT $^{57}$.

Sin embargo, a pesar de esos mecanismos, lo cierto es que los estados no están respondiendo eficazmente a los desafíos que plantea el nuevo sistema de relaciones internacionales. Y es que en un contexto de globalización como el actual, "los Estados parecen demasiado pequeños respecto de los grandes problemas, y demasiado grandes en relación a los de la vida cotidiana, con lo que asistimos a un debilitamiento del exclusivismo de los Estados, e incluso de la relevancia de su papel en las relaciones internacionales" (...) "Los Estados, además, se ven puestos en cuestión al comprobarse que son incapaces de resolver - por sí mismos- problemas que exigen un esfuerzo de cooperación internacional, y al verificarse que existen otras entidades no estatales, como las empresas transnacionales, que operan con creciente relevancia en la vida

54 El fallo está previsto para los próximos meses y cuando se conozca será posible comprobar si como vienen adelantando algunos autores el tribunal arbitral incluye las cuestiones ambientales dentro del fallo o no; con ello se abriría un interesante camino para activar responsabilidad en materia ambiental contra estados y otros sujetos a través de caminos no solo internos, y a través de fuentes que salen de los rígidos marcos que impuso el art. 38 ECIJ.

55 Una política eficaz para la atracción de inversiones en un país con grandes recursos energéticos debe incluir necesariamente un plan de acción que permita identificar y solucionar potenciales disputas, así como asegurar una respuesta eficiente y coordinada del Estado en caso de controversias con inversionistas. Cfr. Alfredo Bullard, "Peru", en Latin American Investment Protections. Comparative Perspectives on Laws, Treaties, and Disputes for Investors, States and Counsel, eds. J. C. Hamilton, O. E. García-Bolivar \& H. Otero (Leiden: Brill-Nijhoff, 2012), 485-534.

56 Que como su art. 3 dispone se aplicará a: “a) Acuerdos celebrados entre Entidades Públicas e inversionistas nacionales o extranjeros en los que se confiera derechos o garantías a estos últimos, tales como contratos de privatización, contratos de concesión, convenios de estabilidad jurídica, licencias de explotación de hidrocarburos, y en general todos aquellos acuerdos que se señalen en el reglamento de la presente Ley que remitan a mecanismos internacionales de solución de controversias. b) Tratados que contengan disposiciones en materia de inversión, celebrados por el Estado peruano con otros Estados y que establezcan procedimientos de solución de controversias entre los inversionistas de un Estado y el Estado receptor de la inversión”. La ley está específicamente destinada a establecer un protocolo de actuación cuando la controversia inversionista-estado es inminente, pero no parece tener pocos efectos sobre la adecuada implementación interna de los tratados de inversión, punto de origen de la mayor parte de controversias. Una norma que se convierte en letra muerta si no va acompañada de un efectivo y eficaz conocimiento de las reglas que manejan en sede internacional, el cumplimiento de las obligaciones surgidas de los acuerdos de inversión. Sobre la importancia de arbitrar adecuados mecanismos de recepción del tratado que "aligeren" las obligaciones del estado huésped pueden leerse varias interesantes sugerencias en, Walter Kälin, "Implementing Treaties in Domestic Law: from 'Pacta Sunt Servanda' to 'Anything Goes'?”, en Multilateral Treaty-Making, ed. Vera Gowlland-Debbas (The Hague: Kluwer Law. 2000), 111-128.

57 Su carta fundacional define su misión: "to enhance the flow to developing countries of capital and technology for productive purposes under conditions consistent with their developmental needs, policies and objectives, on the basis of fair and stable standards to the treatment of foreign investment." 
"Reflexiones sobre el sistema internacional a través de los tratados de inversión"

Susana Mosquera Monelos

internacional" 58 . Parece que hay consenso entre los especialistas de que un cambio es necesario, aunque aún no deciden dónde hacerlo y con qué intensidad.

\section{Reflexiones finales}

Una primera reflexión de cierre, debe pasar por recordar que el derecho internacional, como toda realidad normativa está vivo y sometido a los cambios que se producen en la estructura social en la que se aplica. Ante un cambio en las reglas de juego de la comunidad internacional, surge la necesidad de adaptación del derecho que la rige. No obstante, aunque no se debe tener miedo al cambio sí resulta indispensable reflexionar sobre las bondades y dificultades que ese cambio implica. En el tema que ocupa estas páginas, el cambio pasaría por una modificación del concepto de sujeto internacional, en aras a favorecer una expansión del mismo que permita un uso más versátil, que pudiese dar cobertura a esos actores no estatales que en estos momentos mueven los resortes internacionales desde bambalinas. Los autores se preguntan, ¿debe el derecho internacional dar personalidad jurídica a las empresas multinacionales - dada su intervención en la creación y cumplimiento de ese derecho? ${ }^{59}$, o ¿debe dejarse la creación de estas entidades en manos del derecho interno?

Surge entonces una segunda reflexión que pone en consideración el hecho de que, las empresas multinacionales, a día de hoy, no son sujetos internacionales pero eso no les impide activar el cumplimiento de ciertas normas de derecho internacional, porque les son directamente aplicables. Lo importante es comprender que el estado es el receptor de esas obligaciones y debe aprender a lidiar con ellas en sede nacional - dando una adecuada implementación al tratado ${ }^{60}$, y en sede internacional, -acudiendo a defenderse con los mejores argumentos ante los sistemas de solución de controversias ${ }^{61}$. Por tanto, la respuesta que propone en estos momentos la doctrina $^{62}$ a la cuestión de la subjetividad de las empresas multinacionales, no pasa por expandir

58 Cit. Juan Antonio Carrillo, "Globalización y orden internacional”, en Globalización y derecho. Reflexiones desde el Seminario de Estudios Internacionales 'Luis de Molina', coord. Juan Catalina y Juan Ortega (Cuenca: Universidad de la Mancha, 2003$), 28$.

59 Así como las ONG nacen en derecho interno y se pueden internacionalizar a través de su trabajo y del status consultivo que le ofrecen las organizaciones internacionales también podría suceder con las empresas multinacionales que salen del ámbito jurídico territorial de su estado y se transnacionalizan.

60 No hay que olvidar que derecho internacional y derecho interno son las dos caras del mismo ordenamiento del estado. Tienen por destinatarios a las estructuras internas y a los distintos operadores jurídicos nacionales. Que a veces sea necesario 'traducir' el tratado al derecho interno no significa que se trate de dos fuentes autónomas, sino todo lo contrario.

61 Sin escudarse en argumentos de derecho nacional ya superados desde hace tiempo.

62 Cfr. Beth Stephens, "Are Corporations People? Corporate Personhood under the Constitution and International Law", Rutgers Law Journal 44(1) (2013): 1-38. Vid. José Antonio García, "Las empresas multinacionales como actores autónomos de las relaciones internacionales", Revista de Estudios Internacionales 1 (1980): 355-371. Vid. Claudio Rodríguez, "Empresas transnacionales como vehículos de políticas comerciales internacionales: ¿nuevos sujetos 'atípicos' del derecho internacional público?”, Jurídica 34 (2004): 29-43. Vid. Romualdo Bermejo, "Las empresas transnacionales como actores y sujetos 'potenciales' de la sociedad internacional", en $A A V V$. Perspectivas actuales de los sujetos de derecho, (Madrid: Dykinson, 2012), 89-116.

Número de página no utilizable para citar 
el concepto de sujeto internacional, sino por lograr que el estado -y también las empresas multinacionales-, acepten las obligaciones que derivan de una norma internacional.

Para la tercera reflexión hay que regresar al concepto de partida de esta exposición: el derecho internacional existe, -negarlo sería un despropósito intelectual-, y su objeto -por más utópico o inalcanzable que les parezca a algunos- es lograr bienes que perfeccionan a la comunidad global -aunque para hacerlo haya que sacrificar a veces algunos intereses particulares-. Con las reglas del derecho internacional clásico solo jugaba el estado, de su consentimiento dependía la aparición de normas con fuerza coactiva. Pero tal como se ha tratado de exponer con el ejemplo de los tratados de inversión, en el momento actual, el sistema de fuentes de derecho internacional se completa con una larga lista de normas que no reciben su fuerza vinculante del expreso consentimiento de los estados: a través de reglas consuetudinarias, precedentes establecidos en laudos arbitrales anteriores, cláusulas contractuales que derivan del marco de desarrollo de un acuerdo de inversión y que se adscriben a él, ius cogens internacional aplicable a las responsabilidad criminal de las empresas multinacionales, etc. El soft law es la prueba evidente de que un nuevo sistema de derecho internacional es posible. Si el derecho internacional puede surgir sin la participación del sujeto primario -el estado-, el concepto de subjetividad internacional pierde un poco de importancia, para dar entrada a la efectividad de cumplimiento de la norma y a los resortes de reclamación de responsabilidad por su incumplimiento. Ese soft law deberá encontrar caminos originales para activar su cumplimiento, ya sea en sede judicial interna o a través del acceso a mecanismos de solución de controversias en sede internacional, cuando sea posible; pero sin renunciar a su función vertebradora de una relaciones dispares como son las que inicia el estado con los actores no estatales de naturaleza empresarial. El diálogo interjurisdiccional es perfecta expresión de la gran utilidad que tiene ese uso flexible del sistema de fuentes y aunque alejado del sistema de precedentes, el derecho internacional público actual acude a esa lectura judicial cada vez con mayor frecuencia y acierto.

Cuarta reflexión, la utilización de la norma internacional convierte al agente en actor internacional. No ha creado la norma, pero la está aplicando y con ello está participando del sistema. De manera que la regla, sujetos-consentimiento-fuente, sea reemplaza por la regla norma-cumplimiento-responsabilidad. Esa activación de la norma puede producirse en sede internacional o en sede local, porque los primeros órganos de cumplimiento del derecho internacional son los órganos del estado. El derecho interno ofrece la infraestructura para la aplicación coactiva del derecho internacional. Reafirmando la visión kelnesiana de unidad entre ambos sistemas, frente a las tesis que niegan dicha unidad para, de paso negar validez al derecho internacional. 